\title{
Na Era da Expertise: Formação e Qualificação dos Servidores Públicos durante a Segunda Guerra Mundial
}

\author{
At the Age of Expertise: Training and Qualification of Civil Servant's \\ during the Second World War period
}

\section{Fernanda Lima Rabelo*}

Resumo: Este artigo busca analisar os projetos e discursos de institucionalização da carreira de servidores técnicos federais, propostos pelo Departamento Administrativo do Serviço Público (DASP), entre 1938 e 1945. A partir da visão da formação de núcleos de funcionários administrativos altamente qualificados e na proposta de novos concursos públicos, procura-se entender como o discurso do mérito, da expertise e da eficiência estava ligado à formação de novos quadros de trabalhadores no serviço público no Estado Novo. Objetiva-se, ainda, compreender como o Departamento se posicionou no período da Segunda Guerra Mundial, participando de um projeto varguista de cooperação e alinhamento com o governo norteamericano, durante o conflito.

Palavras-chave: DASP; Estado Novo; Segunda Guerra Mundial; expertise.

Abstract: This article analyzes the project and discourse of institutionalization of the career of technical civil servants, proposed by the Administrative Department of the Public Service (DASP), between 1938 and 1945. DASP sought to create a body of highly qualified administrative employees and opened public competitions in Brazilian civil service. Therefore, we seek to understand how the discourse of merit, expertise and efficiency shaped the new civil service and servant's qualification in the New State's regime. This article also seeks to understand how DASP has positioned itself in the Second World War period, being part of a government project of alignment with the United States during the conflict.

Keywords: DASP; Varga's New State; Second World War; expertise.

Professora e pesquisadora na área de História Contemporânea, do Instituto Federal de Educação, Ciência e Tecnologia Fluminense. Desde 2017, é Visiting Research Fellow no Spanish, Portuguese and Latin American Studies Department na University College Cork, Irlanda. E-mail: fernandalr@gmail.com. ORCID: https://orcid.org/0000-0001-6554-5210 


\section{Introdução}

As discussões recentes relativas ao papel da expertise na formulação de políticas públicas têm levado a debates constantes, entre meio acadêmico e população civil, especialmente por trazer à tona questões relativas à especialização do conhecimento e o que ela traz de benefícios à sociedade. ${ }^{1} \mathrm{O}$ debate se estende, ainda, a questões ligadas a movimentos contra vacinação, negação de relatórios ambientais sobre aquecimento global, desmerecimento de análises sociais e políticas conjunturais, de dados estatísticos e históricos, ancorados no questionamento da relevância do conhecimento especializado, exercida por determinados profissionais no desenvolvimento de ações do Estado. Estas discussões nos remetem, de forma oposta, a um momento da História em que a expertise e a especialização do conhecimento começaram a se tornar elementos fundamentais de legitimação de políticas públicas no mundo do trabalho.

O primeiro objetivo deste artigo é investigar um momento da história política do país, em que o discurso da importância da expertise tomava forma no serviço público, nas décadas de 1930 e 1940, seguidas pela institucionalização da formação de quadros de funcionários e aperfeiçoamento de servidores, nas décadas de 1950 e 1960. Entendendo que o discurso da expertise foi essencial para legitimar políticas públicas de um departamento específico, o Departamento Administrativo do Serviço Público (DASP), entre 1937 e 1945, então ancoradas na visão de eficiência e do mérito na formação de quadros de servidores, procura-se, a partir da análise do discurso de funcionários do DASP, à época, entender o discurso da expertise e do mérito na formulação de políticas institucionais daquele Departamento.

O segundo objetivo deste artigo é compreender como as mudanças propostas foram fundamentadas pelo conhecimento adquirido a partir do primeiro intercâmbio institucional no país, criado pelo Departamento por meio do Decreto n. 776 , de 8 de outubro de 1938, chamado Missão de Estudos no Estrangeiro, em um alinhamento estratégico com os Estados Unidos no período da Segunda Guerra Mundial (193945). Com esse intercâmbio, o DASP buscava promover, entre o funcionalismo

\footnotetext{
O título e tema deste artigo foram inspirados pelo importante livro de Steven Brint (BRINT, Steven. In an age of experts: the changing roles of professional in politics and public life. Princeton: Princeton University Press, 1994), no qual o autor analisa de forma crítica o papel político de experts nos Estados Unidos, a partir do surgimento de experts associados à políticas de Estado. A discussão relativa ao papel de experts na formulação de políticas públicas do Estado retornou a ser debatida nos últimos anos, especialmente neste país e, recentemente, no Brasil. Este artigo teve também como inspiração no seguinte artigo: NICHOLS, Tom. How America lost faith in expertise. Foreign Affairs, v. 96, n. 2, p. 63-73, 2017. Nele o autor debate a formulação de uma nova dinâmica entre o Estado e os acadêmicos, na qual estes últimos atores perdem cada vez mais espaço na arena de formulação de decisões do Estado.
} 
administrativo federal, qualificação em outros países, com o objetivo de adquirir conhecimento nas áreas específicas de cada servidor e especialmente em métodos e práticas administrativas, para aplicar no Brasil. É possível entender que, desde o seu surgimento, o DASP visionava aplicar no país o modelo norte-americano, o qual, com o alinhamento na guerra, se tornou praticamente o único país a ter servidores brasileiros enviados na missão, que iam para universidades e departamentos públicos norte-americanos para estudar teorias e práticas administrativas.

Dessa forma, para compreender a construção de políticas públicas na administração pública federal e o papel, tanto político, quanto administrativo do DASP na formação de quadros qualificados nesse período, é preciso retomar algumas discussões relativas à visão da meritocracia e da institucionalização do serviço público, que ganhava contornos na década de 1930 no Brasil.

\section{O surgimento de políticas públicas para formação de quadros de servidores}

A administração pública, no período denominado Primeira República (18891930), foi marcada por uma reestruturação política e, ao mesmo tempo, pela manutenção de uma antiga ordem, na qual a formação e especialização dos serviços públicos ocorriam sem um planejamento centralizado do Estado. Entretanto, apesar de considerado por muitos autores como um período com poucos avanços em reformas, compreende-se que nesse momento houve uma tentativa de realizar reformas de Estado vinculadas à formação de quadros na administração pública, em um movimento especialmente ditado por setores da classe média do país - militares, sanitaristas e educadores - que pensavam na modernização da nação e no desenvolvimento de reformas dos serviços, sobretudo a partir de $1910^{2}$.

A instituição do novo governo varguista em 1930 trouxe rupturas políticas e também uma nova visão de Estado, cujo caráter reformista era essencial no processo de legitimação do poder. Getúlio Vargas (1930-1945) criou novos ministérios, numerosos departamentos e comissões e apontou novos caminhos para 0 desenvolvimento de políticas nacionais, promovendo reformas na organização de serviços públicos no país, nos âmbitos federal, estadual e municipal.

$\mathrm{Na}$ esfera administrativa federal, as reformas empreendidas pelo governo, a partir de 1935, relacionavam-se à necessidade do então chamado "reajustamento" ou consolidação de uma nova regulação da administração pública, de cargos, de

2 BOMENY, Helena. Novos talentos, vícios antigos: os renovadores e a política educacional. Estudos Históricos - Os anos 20, Rio de Janeiro, v. 6, n. 11, p. 24-39, 1993. 
salários e de funções. Com a criação da Subcomissão Nabuco, pelo Congresso Brasileiro, em 25 de setembro de 1935, foi feito um estudo para avaliar o andamento dos serviços públicos. ${ }^{3}$ Esse estudo incluía a classificação de cargos, os problemas salariais, a criação de métodos de seleção do funcionalismo e o universalismo de procedimentos nas repartições, tarefas consideradas primordiais no Estado varguista para o desenvolvimento de políticas nacionais, sob o discurso da modernização e da extinção do clientelismo existente no período então chamado de República Velha.

A partir do desenvolvimento do trabalho dessa Comissão, no ano seguinte foi criado o Conselho Federal do Serviço Público Civil (CFSPC). ${ }^{4}$ Este Conselho foi instituído de poderes sobre quase todos os ministérios e deveria colocar em práticas ações efetivas que trouxessem mudanças para os órgãos públicos federais. Devido às suas funções e ao grau de importância que o governo deu a essas mudanças, não demoraria muito tempo para que ele se transformasse em departamento.

Em 1938, o CFSPC se transformou em um novo departamento cuja função era organizar, direcionar e padronizar o serviço público brasileiro, o Departamento Administrativo do Serviço Público, o DASP, 5 foi considerado um departamento dotado de poderes especiais, com funcionários especializados no exterior que se tornaram chefes de seções e divisões e que coordenavam os aspectos ligados a planos de carreiras, qualificação e gastos ligados ao serviço público federal. ${ }^{6}$ Foi idealizado para se tornar um departamento modelar, exemplo de eficiência e mérito no país. Porém, acabou se tornando um departamento de expertise insulada. ${ }^{7}$ Dentre dos seus objetivos estava a função de reorganizar ministérios e outros departamentos públicos nacionais, em um plano ambicioso e voltado para a administração em todos os níveis: federal, estadual e municipal. Além disso, alinhado a uma reforma orçamentária, ele buscava dinamizar os departamentos, conduzindo concursos públicos, reexaminando

3 WAHRLICH, Beatriz M. De S. Classificação de cargos e implantação do sistema de mérito: a lei do reajustamento de 1936, suas origens, conteúdo e primeiras repercussões. Revista de Administração Pública, Rio de Janeiro, v. 10, n. 3, p. 7-46, 1976.

4 BRASIL. Lei n. 284, 28 de outubro de 1936.

5 BRASIL. Lei n. 579, 30 de julho de 1938.

6 RABELO, Fernanda Lima De experts a bodes expiatórios: identidade e formação da elite técnica do DASP e a reforma do serviço público federal no Estado Novo (1938-1945). 2013. Tese (Doutorado em História Social) - Universidade Federal do Rio de Janeiro, Rio de Janeiro, 2013. p. 82.

7 Utiliza-se como referência a visão de insulamento burocrático de Edson Nunes (2010), na qual ele retoma a ideia de que a reforma e formação de centros de expertise no serviço público, devido ao patrimonialismo e clientelismo presentes na administração, acabaram levando a um insulamento burocrático, com a criação de um "núcleo" considerado fortemente preparado e que produzia relatórios técnicos, porém não conseguia efetivar suas ações em um âmbito prático, devido à institucionalização de práticas patrimonialistas e, no caso do DASP, centralização de ações. NUNES, Edson de O. A gramática política no Brasil: clientelismo e insulamento burocrático. 4. ed. Rio de Janeiro: Garamond, 2010. p. 80-82. 
repartições, serviços e número de servidores, produzindo métodos mais eficientes para diminuir a chamada burocracia estatal e os gastos.

Entende-se que a reforma administrativa empreendida pelo DASP, no serviço público brasileiro durante o período do Estado Novo (1937-1945), foi inspirada nos princípios da administração científica (scientific management) e de gestão de pessoas (personnel management), teorias científicas ligadas à administração que surgiram no início do século XX. Apesar do scientific management ser uma teoria de organização administrativa fortemente criticada já nas décadas de 1930 e 1940, em países como Grã-Bretanha e Estados Unidos, ela reforçava princípios de eficiência por meio da adoção de regras para agilizar serviços e de princípios burocráticos universais. ${ }^{8}$ Dessa forma, ela se encontrava amplamente difundida na administração pública nesses países. Já as teorias de personnel management surgiram no mundo após a Primeira Guerra, em uma tentativa de produzir novas formas de relacionamento no ambiente laboral, gerenciar o trabalho pessoal, construir fluxos de atividades e gerir de forma eficiente quadros de funcionários. ${ }^{9} \mathrm{~A}$ administração era, de uma forma geral, vista como um organismo funcional, que necessitava de ordem e normas que estabelecessem essa organicidade. Essas teorias se tornaram presentes na administração pública norte-americana na década de 1930.

A criação do CFSPC e do DASP ocorreu em um contexto político específico no qual Brasil e Estados Unidos estreitavam as relações comerciais, culturais e políticas, no período Segunda Guerra Mundial (1939-1945). Para reforçar a ideia de modernização, o governo buscava modelos externos que incluíam, em suas práticas, referências do país ou de países europeus. Dentre as constantes visões de serviço público, estava a adoção de técnicas de outras realidades administrativas no Brasil. Assim, com a finalidade de realizar a capacitação e qualificação de servidores no exterior, em 7 de outubro de 1938 foi promulgado o Decreto-lei n. 776, de 1938, que dispunha sobre "o aperfeiçoamento e especialização dos funcionários públicos no estrangeiro". ${ }^{10}$ Conhecida e divulgada em documentos oficiais como Missão de Estudos e Aperfeiçoamento no Estrangeiro, ela estabelecia a viagem de funcionários públicos de administração federal ao exterior para aperfeiçoamento e, em seu artigo $2^{\circ}$, ficava atribuído ao DASP o papel responsável pela organização dessas missões. ${ }^{11}$

\footnotetext{
TAYLOR, Frederick. Principles of scientific management. [S.I.]: Read Classic, 2001. p. 7.

9 GULICK, Luther. Ensayos sobre la ciencia de la administración. Memorandum preparado em su condición de membro del comité presidencial de gerencia administrativa. [S.I.: s.n.] 1937.

10 BRASIL, 1938, op. cit.

11 RABELO, op. cit., p. 86-87.
} 
A partir de então, dezenas de funcionários federais foram enviados para o exterior, exclusivamente para os Estados Unidos, para capacitação em técnicas e teorias administrativas a serem multiplicadas nas repartições brasileiras. As iniciativas de qualificação por meio de intercâmbio de técnicos administrativos foram desenvolvidas ao longo das décadas de 1930 e 1940, em comum acordo com o governo dos Estados Unidos. As negociações bilaterais ligadas aos interesses de Washington, na conhecida "política da boa vizinhança",

Acabaram promovendo maior contato entre funcionários públicos dos dois países, disseminando teorias administrativas que se constituíram como cerne de reformas de práticas do serviço administrativo no Brasil, fortemente baseadas nos princípios da expertise e da eficiência. Além disso, serviram como um instrumento fundamental da chamada 'política da boa vizinhança' no momento anterior à Segunda Guerra. ${ }^{12}$

Essa interlocução foi vista com entusiasmo por diversos setores do governo brasileiro, pelo diretor do DASP, Luis Simões Lopes, ${ }^{13}$ e pela equipe de técnicos administrativos que coordenava o Departamento. Todavia, foi motivo de críticas dos ministérios, que viam com ressalvas a busca por modelos externos e que não coadunavam com os princípios de controle e métodos científicos adotados pelo Departamento. O programa de aperfeiçoamento no exterior também beneficiou, em particular, os servidores do DASP, que, em grande número, participavam das próprias seleções. ${ }^{14} \mathrm{~A}$ reforma administrativa proposta pelo governo tinha um objetivo claro: substituir as velhas estruturas de poder e trazer uma visão mais compatível com o discurso de modernização varguista. Além disso, buscava trazer mais racionalidade à administração pública, que incluía racionalização orçamentária, estudos de avaliação de eficiência no serviço público e criação de métodos que substituíssem antigas práticas consideradas "patrimonialistas" pelo novo governo, sob o discurso da neutralidade, da expertise e da meritocracia. Tal tarefa foi dada aos funcionários do DASP, que se tornou o órgão central na formulação da nova visão do serviço público brasileiro à época.

Até a saída de Vargas do poder, em 1945, o DASP teve o papel de organizar uma nova administração pública e foi, portanto, uma instância essencial na formulação de práticas do trabalho em repartições públicas. A partir de então, o

12 RABELO, op. cit., p. 94-97.

13 Luis Simões Lopes foi servidor do Ministério da Agricultura, chefe de gabinete de Getúlio Vargas e diretor da Comissão de Reajustamento do Serviço Público. Após assumir o cargo de presidente do CFSPC e do DASP até 1945, permaneceu como figura forte no governo varguista, uma vez que o DASP era ligado diretamente à Presidência da República. Assumiu a presidência da Fundação Getúlio Vargas, criada em 1944, permanecendo no cargo por 48 anos. (RABELO, op. cit., p.134).

14 RABELO, op. cit., p. 120-121. 
Departamento e sua reforma foram se enfraquecendo, à medida que a centralização burocrática perdeu o apoio da Presidência.

Mesmo que centralizadora e, consequentemente, questionada por parte dos servidores de ministérios e departamentos federais, a reforma empreendida pelo DASP possibilitou a criação e ampliação de cursos de aperfeiçoamento de técnicos administrativos e os primeiros concursos públicos em larga escala no país. Porém, na tentativa de criar uma nova mentalidade burocrática, ou "cultura científica" no trabalho, baseada em padrões de eficiência e produtividade, o Departamento adotou regras rígidas dentro do funcionalismo, que não via com bons olhos a burocratização de atividades e de suas ações. Produziu, também, com efeito, um corpo técnico insulado e que tentava na teoria "extirpar o patrimonialismo" do serviço público, quando na prática produziu novas formas de relacionamento, substituindo antigos pares políticos por outros que coadunavam com o governo então vigente.

Em trabalho relacionado à burocratização, profissionalização e a busca pelo mérito no serviço público, D. Bonis e Regina S. Pacheco (2010) reforçam a visão de que a década de 1930 foi o momento de expansão das capacidades administrativas do país, momento no qual se buscou adotar regras de regimes burocráticos balizadas na visão do mérito (concursos públicos). Em uma análise dos problemas nos quais o governo esbarrou na criação de um sistema de plano de carreiras e ingresso no serviço público, está a politização da máquina pública, por meio do clientelismo, e uma reforma que foi, na visão dos citados autores, inacabada. ${ }^{15}$

Analisando, ainda, as intenções da reforma, Edson Nunes, a partir da avaliação da política varguista, reforça que o Presidente relacionava a manutenção institucional com o conhecimento técnico. Dessa forma, ele instituiu um clientelismo que favorecia seus pares e atribuía a estes o papel de destaque na reforma. Às antigas lideranças políticas, Vargas associava à imagem de corrupção, de apatia funcional e de morosidade na burocracia. O Estado varguista, por outro lado, ancorado em bases técnicas e científicas, lançava mão de novas prerrogativas, enquanto, na verdade, as antigas nunca deixaram de existir. ${ }^{16}$

Eli Diniz (1999), por sua vez, ressalta que na nova engenharia político-social do Estado Novo, o que ocorreu, por trás de um discurso cientificamente embasado e de neutralidade do Estado nas decisões burocráticas, construiu uma nova

15 BONIS, D.; PACHECO, Regina Silvia. Nem político, nem burocrata: o debate sobre o dirigente público. In: ABRUCIO, Fernando; LOUREIRO, Maria Rita; PACHECO, Regina Silvia. (org.). Burocracia e política no Brasil: desafio para o estado democrático no século XXI. Rio de Janeiro: Ed. FGV, v. 1, p. 273-295, 278, 2010.

16 NUNES, op. cit., p. 81-82. 
modalidade de articulação entre o mundo dos interesses e a esfera estatal. Dessa forma, produziu-se uma estrutura vertical, com atores insulados em altos cargos, que participavam das decisões diretamente ligadas ao executivo, representados por setores ligados às elites urbanas e a empresários industriais. ${ }^{17}$

Ainda em relação à dinâmica política estadonovista, Ângela de C. Gomes (1999) avalia que o Estado Novo estabeleceu uma nova relação entre a ideologia política e o sistema de regras legais. O discurso reforçava o valor das leis, comprovado por projetos político-institucionais, e era direcionado a um público alvo - a classe trabalhadora. O que se produziu, na verdade, foi uma elaboração de políticas públicas voltadas para esta classe, com a construção do discurso de "um homem novo". ${ }^{18}$ Assim, a apropriação desse novo discurso, associava-o a uma nova racionalidade técnica, a partir das diferentes frentes institucionais criadas por Vargas, enfatizando a modernização do sistema e expurgando a imagem de clientelismo vinculada à sua administração.

$\mathrm{Na}$ análise do papel do DASP na promoção do mérito por meio de concursos é possível compreender que o Departamento, desde a sua criação, tinha com objetivo alcançar a racionalidade e a eficiência, a partir da formação de quadros de servidores considerados experts no serviço federal. Porém, acabou produzindo ações que, apesar do discurso de neutralidade política, também estavam alinhadas com o autoritarismo varguista e com a substituição de quadros na esfera de decisões, mantendo-se clientelista.

Assim, é possível compreender que antigas prerrogativas políticas nunca deixaram de existir no serviço público. Desde o início de suas atividades, a equipe, em cargos de chefia no Departamento, tinha objetivos políticos claros: produzir uma visão sobre si mesmo de eficiência, a partir do discurso do mérito, do conhecimento técnico e da formação de quadros de servidores considerados especialistas e, portanto, detentores de um conhecimento cientificamente comprovado. Entretanto, geraram, um insulamento burocrático entre seus pares e se mantiveram no poder por meio dos mesmos laços associativos que existiam antes do período varguista, sendo associados, ainda, fortemente ao seu presidente, Luis Simões Lopes, e ao autoritarismo do Estado Novo.

17 DINIZ, Eli. Engenharia institucional e políticas públicas: dos conselhos técnicos às câmaras setoriais. In: PANDOLFI, D. (org.). Repensando o Estado Novo. Rio de Janeiro: Ed. FGV, 1999. p. 28.

18 GOMES, Angela de C. Ideologia e trabalho no Estado Novo. In: PANDOLFI, op. cit., p. 57. 


\section{A missão de estudos e aperfeiçoamento no estrangeiro e o Brasil na guerra}

A construção de uma nova imagem da administração pública brasileira, considerada atrasada, extremamente burocratizada e afetada pelo clientelismo do DASP, era o ponto principal de preocupação de Luis Simões Lopes e dos servidores de chefia do Departamento, que, durante as décadas de 1930 e 1940, buscaram transformar em discurso e práticas uma nova imagem do serviço público brasileiro.

A missão de estudos e aperfeiçoamento no exterior, instituída por decreto em 1938, viabilizou a viagem de servidores federais brasileiros para estudar e fazer treinamento em universidades e departamentos públicos nos Estados Unidos, em especial na American University, em Washington D.C., e na Civil Service Commission, departamento norte-americano cujo papel era similar ao DASP, também na capital norte-americana. A missão poderia ser realizada em qualquer país no exterior e os funcionários interessados de todos os ministérios e repartições federais deveriam se inscrever no processo seletivo da Divisão de Seleção do DASP. Apesar de o decreto estabelecer que a missão poderia ser realizada em qualquer país, é possível dizer que o próprio Luis Simões Lopes buscava, desde a criação do CFSP, criar parcerias com o governo norte-americano, solicitando informações sobre a administração pública daquele país pela embaixada brasileira em Washington D.C., além de enviar quatro servidores como teste, em 1937, para estudos na capital norteamericana. ${ }^{19} \mathrm{~A}$ partir dessa missão, foi possível ver o delineamento da construção de uma política de aproximação com os Estados Unidos pelo DASP.

Após a institucionalização das missões, o DASP passou a enviar anualmente dez servidores para os Estados Unidos. A universidade que mais recebia estudantes, a American University, havia criado um programa de especialização em administração pública para receber estrangeiros chamado Hall of Nations. ${ }^{20}$ Neste, servidores de qualquer país interessados em estudar a realidade administrativa norte-americana poderiam se inscrever. Foram enviados servidores também, em menor número, para outras universidades, em Nova lorque (Syracuse University e Columbia), na Califórnia (University of Southern California e University of California, Berkeley) e em Chicago (University of Chicago). ${ }^{21}$ Apesar da variedade de universidades escolhidas por

19 CARTA de Luiz Simões Lopes, entre 1936 e 1937. LSL 1935.08.14 APU - Dossiê DASP, Cpdoc, FGV, Rio de Janeiro.

20 Foi possível visualizar apenas um estudante que foi para a Grã-Bretanha, em 1946. Subsérie Pessoal. Série: Aperfeiçoamento. Aperfeiçoamento no exterior. Pasta 672. Fundo DASP, Arquivo Nacional, Rio de Janeiro.

21 Pastas 663-672, Fundo DASP; Diários Oficiais da União (anos de 1937 a 1946), Caixas 1 e 2 do Programa Hall of Nations, SPA, American University, Ofícios expedidos e recebidos entre DASP e 
servidores brasileiros, a American University, realizava parcerias com departamentos públicos norte-americanos. Assim, trazia vantagens ao DASP, pois os servidores brasileiros poderiam estudar na capital norte-americana e realizar estágio em repartições públicas na capital. Desta forma, ela congregava o que o DASP desejava: o treinamento de funcionários públicos administrativos, a partir da realidade administrativa norte-americana, especialmente da Civil Service Commission, modelo considerado por Luis Simões Lopes o melhor a ser seguido no serviço público brasileiro, para que eles pudessem realizar uma reforma administrativa no Brasil, afastando a imagem de atraso e trazendo uma imagem moderna. ${ }^{22}$

Esse intercâmbio institucional, que previa ainda o recebimento de servidores e professores em administração pública norte-americanos no Brasil, tornou-se ainda mais forte com o início da Segunda Guerra Mundial. Com o progressivo alinhamento brasileiro ao governo estadunidense e com a estratégia de aproximação chamada de "equidistância pragmática" pelo historiador Gerson Moura (1982), ${ }^{23}$ foram criados acordos e canais de negociação para que os países aumentassem seus laços políticos, econômicos e culturais, no final da década de 1930 e início da década de 1940. Dentre um dos canais mais conhecidos de aproximação está o órgão ligado ao Office of War Information norte-americano, o Office of the Coordinator of InterAmerican Affairs (OCIAA). ${ }^{24} \mathrm{O}$ Departamento foi, assim, responsável por construir parcerias, como trocas comerciais, intercâmbio educacional e cultural, produções culturais, além de viabilizar projetos de envergadura sanitária, comercial e industrial (como o financiamento da construção da Companhia Siderúrgica Nacional e a autorização para a construção de bases aéreas norte-americanas no Nordeste, em Natal e Fortaleza).

Para além das ações de parceria econômica, o período da Segunda Guerra foi marcado pela construção ideológica de aproximação dos Estados Unidos com países da América Latina. A busca por aliados compreendia não somente realizar acordos, mas "expurgar" a ameaça nazista do continente, sob a bandeira da liberdade política, econômica e individual norte-americana. Havia uma preocupação clara do governo norte-americano com o governo autoritário varguista e que um alinhamento político

Itamaraty (1936-1946), Revistas do Serviço Público (de 1937 a 1945) e Arquivo Luiz Simões Lopes (LSL), CPDOC, FGV.

22 É importante ressaltar que já havia envio de servidores para estudo no exterior, efetuado pelo Itamaraty, até a promulgação do Decreto n. 776/1938. A partir de sua criação, o DASP se tornou exclusivamente responsável pela aprovação da ida de funcionários ao exterior em missões de estudo, prerrogativa que manteve até 1945 e a saída de Vargas do poder. (RABELO, op. cit., p. 97).

23 MOURA, Gerson. Foreign relations 1939-1950: The changing nature of Brazil-United States relations during and after the Second World War. London: University College London, 1982.

24 RABELO, Fernanda. A Hollywood da boa vizinhança: imagens do Brasil em documentários norteamericanos na Segunda Guerra. Jundiaí, SP: Paco, 2018. p. 71. 
entre Brasil, Argentina e Alemanha pudesse afetar o continente na guerra. Tanto o OCIAA, quanto o Departamento de Estado, além de embaixadas e parceiros políticos do governo norte-americano (alguns deles industriais ou magnatas, com forte poder de investimento na América Latina, como o Nelson Rockefeller, que se tornou o coordenador de ações do OCIAA) estavam empenhados em reforçar a aproximação dos países americanos, a partir do discurso do pan-americanismo, e por meio da obtenção de apoio ideológico e político, no período da guerra. Nesse sentido, o DASP, sob a figura de Luis Simões Lopes, atuou fortemente na concretização de acordos entre os dois países. Ele realizou viagens aos Estados Unidos e firmou parcerias com universidades brasileiras com o fim de treinar servidores em práticas administrativas.

Lopes previa, ainda, que além do envio de servidores brasileiros para os Estados Unidos, servidores e professores viessem ao Brasil para ensinar técnicas administrativas no serviço público federal. ${ }^{25} \mathrm{O}$ intercâmbio de técnicos no DASP ocorreu, assim, em duas vias: técnicos administrativos viajaram do Brasil aos Estados Unidos para estudar ou fazer treinamento, e professores norte-americanos vieram ao Brasil, para dar palestras e realizar cursos com os servidores do DASP. Este intercâmbio técnico prosseguiu pela década de 1940, sendo que, em 1945, a Revista do Serviço Público anunciou novamente o trabalho coordenado de especialização de pessoal aos Estados Unidos, considerado o país mais apropriado para receber esses alunos estrangeiros, devido à "racionalidade norte-americana, à aplicação de métodos tayloristas, a organização administrativa e também aos acordos entre as nações, que só aumentaram no período de guerra". ${ }^{26}$

A parceria com a American University foi visível não somente nas discussões relativas ao aprendizado e à aplicação de técnicas administrativas aprendidas no exterior por servidores públicos no Brasil, discutidas na Revista do Serviço Público, como pelo quantitativo de estudantes enviados para realizar o programa. Em documento da universidade de 1949, o Brasil não somente era o país com mais participantes no Programa Hall of Nations, como também enviou quatro vezes mais servidores ao programa do que o segundo país, México, entre 1939 e 1949:

25 Apesar dos esforços do Departamento em trazer servidores norte-americanos ao país, apenas três professores vieram para treinar servidores brasileiros: E. White, John Paterson e Henry Reinings Jr., em 1940, 1942 e 1943. White era professor da American University, Patterson era professor de administração pública da University of Missouri e Reinings Jr., da University of Southern California. (RABELO, 2013, op. cit., p. 192).

26 Revista do Servidor Público, ano 8, 1945, v. 1, n. 1, p. 3-4. 


\section{Quadro 1}

Programa Hall of Nations, 1939-1949

\begin{tabular}{|c|c|}
\hline PAís & NÚMERO DE ESTUDANTES \\
\hline Brasil & 54 \\
\hline México & 14 \\
\hline Etiópia & 9 \\
\hline Paquistão & 9 \\
\hline China & 8 \\
\hline Peru & 8 \\
\hline Filipinas & 7 \\
\hline Tailândia & 6 \\
\hline Chile & 5 \\
\hline Haiti & 5 \\
\hline
\end{tabular}

Fonte: Box 1, American University Archives, Washington D.C.

É possível perceber, ainda, o número maior de brasileiros que recebeu certificação do programa no período da Segunda Guerra. No quadro a seguir, é possível visualizar o número de brasileiros certificados entre 1938 e 1946, com número elevado nos anos da guerra:

\section{Quadro 2}

Hall of Nations, distribuição de certificados, 1939-1946 27

\begin{tabular}{|llllllllllllll|}
\hline País & \multicolumn{10}{c|}{ Ano } \\
\hline Brasil & 1938 & 1939 & 1940 & 1941 & 1942 & 1943 & 1944 & 1945 & 1946 & 1947 & 1948 & 1949 & \\
& 4 & 4 & 9 & 7 & 11 & 2 & - & 3 & 1 & 1 & 1 & - & 43 \\
\hline
\end{tabular}

Fonte: Box 1, American University Archives, Washington D.C.

O intercâmbio técnico e administrativo promovido pelo DASP no período da Segunda Guerra fornece ferramentas para pensarmos como as relações políticas entre os países foram delineadas no período. Ganhando importância estratégica e política no governo Vargas, as missões de servidores ao exterior ganharam claros contornos de parceria ideológica, até a concretização de entrada do Brasil na guerra, em agosto de 1942.

27 Nos dados obtidos, não foi possível visualizar os anos de 1944 e 1949.Também não há explicação pelo número de brasileiros ser contabilizado como 54 e em outro documento, 43. É possível que servidores brasileiros não tenham obtido certificação, porém realizaram cursos menores no programa, ou apenas de estágio em repartições. É possível também inferir que o Brasil enviou um número significativo de servidores para estudar no programa, comparado a outros países. 
Também é possível compreender que, por meio desse programa, pôde ser notado um interesse na transformação da administração pública no Brasil, para que a ela se aproximasse aos padrões institucionais norte-americanos, a partir de uma visão de que a modernização da máquina administrativa brasileira deveria ser espelhada nos Estados Unidos. Assim, os objetivos do DASP, para além de ideológico e político no período da guerra, também esbarravam na busca por um quadro de servidores eficientes e que pudesse, por meio de especialização e do aperfeiçoamento, compor quadros de trabalhadores qualificados na administração pública brasileira. Dentre as diversas ações do DASP na qualificação de servidores, está a criação de concursos públicos, os quais se destacaram tanto pela complexidade das seleções, como pela tentativa de padronização de seleções, universalizando procedimentos na administração federal.

\section{Discursos e práticas do DASP: seleções, mérito e a desejada eficiência no serviço público}

Para compreender melhor o papel do DASP na formação e na qualificação de servidores ligadas ao projeto estadonovista, é necessário analisar tanto a realização de concursos públicos pelo DASP, quanto os discursos associados à visão de eficiência e de mérito na formação do funcionalismo público do Estado Novo.

Um dos maiores projetos do DASP foi a criação de novos concursos públicos, considerados pelos seus servidores um de seus "grandes méritos". A prerrogativa de associação da expertise e do mérito com a eficiência no serviço público é fortemente reforçada em todo o período do Estado Novo. Já havia na administração pública servidores federais concursados, especialmente nos ministérios da Agricultura, Fazenda e do Itamaraty, que contavam com processo seletivo próprio. Contudo, o DASP questionava a validade dos concursos já existentes, além do desejo de padronizar os processos seletivos de todas as instâncias do serviço público federal.

As provas de admissão do DASP, junto aos cursos de aperfeiçoamento, eram vistos, como define Gilbert Siegel (1978), como os principais trunfos do Departamento, sendo consideradas exaustivas, complexas e extremamente seletivas. O processo seletivo era tão rigoroso que poucos conseguiam alcançar sua aprovação, independente dos cargos que fossem. Por exemplo, nas funções de manutenção, almoxarifado ou secretariado, exigiam-se conhecimentos específicos de contabilidade, matemática, geografia, cálculo e direito. Entre 1937 e 1943, a Divisão de Seleção organizou concursos públicos para 264 cargos. Dependendo do 
cargo, as provas eram técnicas, complexas e também exigiam amplos conhecimentos gerais. ${ }^{28}$

O concurso para técnico administrativo era organizado pela Divisão de Seleção e Aperfeiçoamento do DASP. Dentre os objetivos dos processos seletivos, tanto para os contratados temporários (extranumerários), como para servidores efetivos, buscava-se nivelar os funcionários federais e, ao mesmo tempo, diminuir o número de servidores extranumerários. O DASP também fazia seleção para extranumerários que já trabalhavam em repartições públicas e ministérios. Caso estes não tivessem um bom desempenho na avaliação, poderiam ser substituídos por novos extranumerários, com melhor desempenho no processo seletivo.

Apesar das dificuldades de ministérios e repartições em aceitar os processos seletivos centralizados, o DASP criou a prerrogativa de organizá-los. Em relatório da Divisão de Seleção de 1943, Murilo Braga, seu diretor, relata a importância dada às seleções para a instituição do mérito no serviço público. Ele menciona que os concursos mudaram a forma de ingressar nos quadros funcionais, trazendo equidade e diminuindo a influência política. Braga reafirma, assim, o importante papel do DASP no combate à ineficiência do aparelho público federal que, através dos concursos, passou a implantar as noções de mérito no serviço público:

Foi preciso criar tudo em todos os campos; e foi preciso, ainda, implantar, em primeiro lugar, como condição necessária, um sistema em que a justiça e a igualdade de tratamento para todos os candidatos, de acordo com a capacidade de cada um, fossem o denominador comum de nossas atividades em seleção, porque bem sabíamos o quanto chegara ao descrédito o regime de concursos no Brasil e o descaso que lhe votavam os mais capazes. $^{29}$

É possível, também, a partir da análise do discurso de funcionários do DASP na Revista do Serviço Público (RSP), perceber que o discurso da expertise do Departamento e sua importância na formação dos quadros no governo federal estavam diretamente ligados à ideia de "modernização" da administração pública.

28 Os conteúdos poderiam ser classificatórios (habilitação) e eliminatórios. Como exemplo da complexidade da seleção, para o cargo de Arquivista, os candidatos faziam prova de conhecimentos técnicos de arquivo e de Português. Além destas, a prova de habilitação incluía Geografia do Brasil, Noções de Estatística, Matemática, tradução de Inglês e Datilografia. No concurso para Bibliotecário, a prova se subdividia em 13 seções, que incluíam: conhecimentos de Direito, Estatística, Ciências Humanas, Francês, Inglês e Ciências da Administração; além disso, o exame ainda exigia provas de habilitação de conhecimentos de Catalogação, Bibliografia, Classificação, Referência, Organização e Administração de Bibliotecas. Para o cargo de oficial administrativo, o DASP exigia conhecimentos em Português, Direto Administrativo, Matemática, Estatística e Noções de Contabilidade e, ainda, era necessário prova de habilitação em Geografia do Brasil, Direito Constitucional, Penal e Civil. (RABELO, op. cit., 2013. p. 87-88).

29 DASP. Relatório da Divisão de Seleção. Rio de Janeiro, 1943. p. 4. Pastas 34 e 35, Arquivo Nacional, Rio de Janeiro. 
A Revista do Serviço Público foi lançada em novembro de 1937 e se constituiu no primeiro periódico de divulgação de um órgão da administração pública federal no país. Lançada pelo CFSPC, a Revista foi um importante meio de divulgação das suas atividades e, posteriormente, das do DASP. Seus artigos, majoritariamente ligados às ações desses órgãos no estabelecimento de uma nova mentalidade no serviço público, foram importantes na difusão dos princípios administrativos advogados à época. A RSP se apresentava como um órgão oficial do DASP e, para além da divulgação de ações administrativas institucionais, entende-se que ela propunha uma "moralização" dos serviços. Composta por artigos de servidores principalmente do Departamento, eles apresentavam opiniões de forte cunho político. Ela também divulgava os princípios do tecnicismo e a crescente racionalização do trabalho.

$\mathrm{Na}$ visão de seus escritores, a racionalização dos serviços só seria viável caso fosse incorporada de forma prática pelos servidores. Ela se baseava no cumprimento de normas nas repartições para eliminar a ineficiência no serviço, através da execução ordenada de tarefas, diminuição de protocolos burocráticos e redução do tempo na distribuição de documentos em cada repartição. As revistas focavam, essencialmente, na racionalização por meio de regras rígidas no ambiente de trabalho.

Desde o início, a RSP mostrou também ter um viés ideológico. O papel político do Departamento e de seus servidores foi fundamental na argumentação editorial. Os próprios servidores do CFSPC e, posteriormente, do DASP se intitulavam "elite" do serviço público. Urbano Berquó, funcionário do Departamento, ressalta em artigo publicado em janeiro de 1938 que os servidores do CFPSC eram funcionários "de alto nível" e que era necessário no Brasil a constituição de "uma elite capaz de realizar com o melhor rendimento esse trabalho verdadeiramente criador [...]" ${ }^{30}$

Benedicto Silva, diretor da Divisão de Receitas do DASP, por sua vez, em texto no qual destacou "a 'espécie de homens' que o DASP necessita[va]", ${ }^{31}$ enfatizou que - Estado considerado moderno precisava de homens técnicos, especialistas que fossem os mais capazes na sociedade para executar os serviços públicos. Dessa forma, tanto Benedicto Silva, quanto Urbano Berquó, avaliaram que o departamento era formado por um grupo especial, uma elite, sob uma visão da expertise como mantenedora do mérito na administração pública:

Dentro do Estado que acabo de bosquejar, que é o Estado real de nossos dias, um órgão do tipo do DASP, órgão pioneiro e de inspiração tão generosa, destinado a recuar fronteiras, tem que contar com a nata da nata. Se o Estado hoje deve recrutar os melhores dentre os seus cidadãos, para Ihes confiar os serviços

30 Revista do Serviço Público, ano 1, v. 1, n. 2, 1938. p. 11.

31 Ibidem, ano 5, v. 1, n. 2, 1942. p. 30. 
públicos, órgão da natureza do DASP, entre cujas finalidades se inclui, precipuamente, a de preparar e dispor os meios para que os ministérios realizem os fins da administração pública, não podem prescindir do concurso de uma verdadeira elite, sob pena de falharem à sua missão. ${ }^{32}$

Assim, Silva e Berquó destacavam a relevância das próprias ações do DASP, articulando o discurso da eficiência com o do mérito e do tecnicismo.

A Revista de agosto do mesmo ano trouxe uma série de artigos redigidos pelos diretores do novo Departamento. Tais artigos descreviam, de forma entusiasmada, os projetos em execução. O discurso do presidente do DASP, Luis Simões Lopes, no ato de posse, reproduzido na Revista, já apontava para a relevância desse grupo na implantação dos projetos administrativos do governo. Os servidores do extinto CFSPC se transformaram em um forte grupo de diretoria do DASP, considerados por Simões Lopes "promotores da nação". 33

Os artigos seguintes relatavam as novas regras e norteamento do DASP, como o escrito por Mario Paulo de Brito, diretor da então Divisão de Seleção e Aperfeiçoamento. Brito dissertou sobre a importância de uma seleção rigorosa do funcionalismo, diminuindo as nomeações e as indicações pessoais. Para resolver o problema da chamada "ineficiência" no serviço público, o servidor declarou que o aperfeiçoamento deveria englobar tanto a formação de servidores antigos, através de cursos, como também concursos de admissão para funcionários novos.

Atribuindo a Getúlio Vargas uma posição flexível e democrática nas nomeações ministeriais, Brito afirmou que o presidente "despojou-se" desta prerrogativa, reafirmando o valor da meritocracia no funcionalismo:

\begin{abstract}
A nova medida que passou a vedar a livre nomeação, tirou das mãos do magistrado supremo a arma até então mais utilizada para alicerçar o prestígio pessoal e político do Presidente da República, de quem, em última instância, tudo dependia, na verdade, porém mais aparentemente do que realmente, dada a trama complicada dos interesses em jogo.

Como quer que seja, porém, o despojar-se voluntariamente dessa prerrogativa, se privou o presidente de um recurso farto e permanente, trouxe-lhe e ao poder público, de que é a expressão máxima, uma soma incalculável de prestígio moral, de alcance talvez ainda não suficientemente aquilatado por toda a sua gente..$^{34}$
\end{abstract}

A instituição do mérito com a percepção de que o próprio Presidente havia se despojado dos poderes de nomeação era fundamental para reafirmar o discurso

32 Ibidem.

33 Ibidem, ano 1, v. 3, n. 2, 1938. p. 10.

34 Revista do Serviço Público, ano 1, v. 3, n. 2, 1938. p. 11 
técnico do novo governo. Porém, mesmo com o sucesso adquirido ao longo dos anos, Vargas continuava nomeando altos funcionários. Portanto, no Estado Novo, Vargas utilizava as mesmas prerrogativas políticas que seus antecessores. $\mathrm{Na}$ prática, o presidente favorecia seus novos pares políticos, em um jogo de negociações que aumentou no período autoritário.

A despeito da ambiguidade entre práticas e discursos do presidente, os funcionários do DASP continuavam ressaltando a impessoalidade institucional como objetivo de um governo comprometido com a modernização do sistema, no qual necessitava centralizar ações. Na edição de agosto de 1938, Moacyr Briggs, funcionário consular do Itamaraty e diretor da Divisão de Organização e Coordenação do DASP, distingue o governo estadonovista e as ações do Departamento, como indispensáveis e não necessariamente indissociáveis de estados autoritários:

E se, antes da outorga da Constituição de 10 de novembro, o Conselho Federal do Serviço Público e Civil era útil, vantajoso, atualmente pode-se afirmar sem exagero que o Departamento Administrativo é um órgão imprescindível, indispensável ao acionamento da máquina administrativa.

Não quer isto dizer que o Departamento seja um organismo próprio dos Estados autoritários. Os Estados Unidos da América do Norte e a Inglaterra, países eminentemente democráticos, possuem o seu Civil Service. É, sim, um órgão imprescindível à racionalização da administração pública. Toda vez que se cogitar de moralizar o serviço civil, no sentido de obter o máximo de eficiência, aí surge nítida e precisa, como consequência indeclinável, a necessidade de um órgão controlador. ${ }^{35}$

A dissociação realizada por Briggs entre o DASP e o Estado Novo, diferentemente da associação feita por Brito, foi importante para reforçar a percepção de isenção política existente no quadro de funcionários pertencentes à chefia e à diretoria do DASP. Ainda nos discursos dos funcionários da direção do DASP é possível perceber a sua ambiguidade em relação ao seu papel como promotor de reformas em um estado autoritário. Se para alguns, como Berquó, o governo varguista deveria ser exaltado, para outros, como Briggs, seu discurso procurou se distanciar da figura de Vargas, pautando-se na ideia de que não necessariamente a centralização de decisões administrativas refletia um governo autoritário.

O destaque dado ao cientificismo e ao racionalismo também era constante na RSP. O DASP seria uma agência exemplar para que estas novas práticas se multiplicassem nos ministérios e nas repartições públicas do Brasil. O exemplo do

35 Ibidem, p. 17. 
Departamento se baseava, ainda, no tecnicismo. Em editorial da RSP, publicado em outubro de 1938, Urbano Berquó destacou as chamadas "diretrizes" que o Departamento e seus funcionários deveriam seguir:

\begin{abstract}
O serviço civil brasileiro, desde que se procedeu à sua estruturação, em conformidade com as diretrizes racionalizadoras da lei n. 284, de 28 de outubro de 1936, não comporta mais a aplicação em seu seio do critério vesgo do nepotismo ou do filhotismo político. O recrutamento de funcionários e as promoções fazem-se hoje exclusivamente em obediência a preceitos claros que equivalem ao reconhecimento daquilo a que os ingleses chamam de merit rule. Essa é, aliás, uma condição indispensável [...] no sentido da completa desburocratização do pessoal administrativo federal. ${ }^{36}$
\end{abstract}

De forma incisiva, o autor relatou que a constituição de uma lei geral de servidores (a Lei n. 284/36, de "reajustamento" do serviço público) e a criação dos órgãos subsequentes que instituiriam a reordenação no serviço público federal seriam fundamentais para a formação da meritocracia e para o fim tanto do clientelismo, quanto do patrimonialismo.

É relevante, também, no estudo do discurso daspiano na RSP, a análise da sua visão sobre a burocracia. Na seção da Divisão de Seleção e Aperfeiçoamento, parte da Vida Administrativa da RSP, o diretor Murilo Braga de Carvalho escreveu artigo intitulado Burocracia e inutilidade: a distância entre duas eras, ${ }^{37}$ no qual afirmava ser injusto atribuir à burocracia aspectos negativos, já que a instauração de novos processos burocráticos nas repartições em nada se assemelhava às antigas práticas:

É injusto e sem lógica dar o mesmo nome a fatos diferentes. Por exemplo, continuar a chamar burocracia, com a mesma velha e merecida intenção pejorativa, o atual serviço público. Há entre a velha e a nova burocracia um abismo, cujo fundo é marcado pela Lei de Reajustamento, fronteira de duas áreas nitidamente distintas. $^{38}$

A defesa da "nova burocracia" se pautava na perspectiva da crescente primazia de processos claros, racionais e metodicamente estruturados, com vistas a maior rapidez e eficiência nos serviços públicos. A atividade burocrática seria eficiente, desde que fosse executada de forma racional. Uma das ações promovidas pelas divisões do DASP, através do seu departamento de publicidade foi criar uma campanha de combate à "ineficiência" no serviço público, com produção de material escrito e ilustrativo, divulgado nas repartições e na Revista do Serviço Público. ${ }^{39}$

\footnotetext{
36 Revista do Serviço Público, ano 1, v. 4, n. 1, 1938. p. 3-4.

37 Ibidem, ano 3, v. 4, n. 1, 1940. p. 211.

38 Ibidem.

39 RABELO, 2013, op. cit., p. 159-160.
} 
Murilo Braga destaca, ainda, a oposição existente entre a administração varguista e do período da República Velha, e como os órgãos no período anterior eram pouco eficientes:

Uma, era o reino do desleixo e do adiamento, onde o interesse público se perdia no labirinto dos canais competentes, da papelada e das informações displicentes. [...] Uma era a província predileta dos humoristas, armazém inesgotável das censuras aos governos. A outra é uma organização que pode sofrer críticas, mas merece respeito. Uma era um peso morto, engrenagem inerte da máquina do Estado. A outra é um elemento propulsor, fator de progresso e garantia de êxito administrativo. ${ }^{40}$

Assim, é possível depreender, a partir da breve análise do discurso dos servidores daspianos, o papel atribuído ao conhecimento científico, à visão do mérito, ao acesso ao serviço público por meio de provas de concursos e à formação de servidores, a partir de novas regras no funcionalismo - que destituíam, em sua essência, a visão clientelista e patrimonialista associada às administrações predecessoras. O que estava em jogo, neste momento, era a formação de uma nova visão de serviço público, baseada na expertise e não na política; na meritocracia e não no patrimonialismo; na eficiência e não na morosidade. Uma visão moderna de administração também deveria levar em conta novos servidores e destituir ações passadas, "expurgando" os chamados "males" das administrações anteriores.

\section{Conclusões}

A RSP era divulgada em todas as repartições públicas federais, na então capital da República, promovendo um discurso renovador, baseado na visão política dos servidores daspianos sobre o que era o mais adequado para a administração pública, porém, com uma nova "roupagem" técnica. As iniciativas do DASP compreendiam cursos específicos para servidores federais em assuntos tributários e legislativos, campanhas culturais e esportivas com os funcionários públicos, orientação técnica para a organização de documentação, gestão de pessoal, redação de memorandos, entre outros afazeres burocráticos. Estas medidas evidenciavam, ainda, que esses servidores tinham uma função técnica e especializada e se concretizavam, também, mediante diversos cursos de capacitação no exterior e no próprio Departamento. Os servidores do DASP ainda promoviam palestras e cursos, incluindo cursos de curta duração, com a participação de professores norte-

40 Revista do Serviço Público, ano III, v. 4, n. 1, outubro de 1940, p. 211. 
americanos ${ }^{41}$ também orientavam os serviços públicos estaduais e municipais em ações administrativas, distribuindo cartilhas e guias burocráticos; e ambicionavam, assim, realizar uma grande "revolução" na administração pública e criar uma visão de si próprios extremamente técnica e destituída do viés ideológico, embora estivessem claramente inseridos na máquina burocrática do Estado Novo e no jogo político institucional.

Afinal, qual foi o papel do DASP na formação de quadros especializados e na formulação de núcleos de expertise nas décadas de 1930 e 1940?

Em um momento de renovação na imagem das institucionais brasileiras, o DASP se tornou um departamento modelar, projetou-se por seu papel estratégico e produziu reformas no mundo do trabalho que, ao mesmo tempo em que aumentou a influência política e administrativa do Departamento, trouxe questionamentos profundos de trabalhadores em outros setores, ministérios e departamentos federais. Quando da saída de Vargas do poder em 1945, o DASP perdeu muito de sua força política. Mesmo com a nova situação, seus servidores permaneceram em cargos estratégicos, com exceção de Luis Simões Lopes, que, apesar de sair do funcionalismo, assumiu o cargo de presidente da recém-criada Fundação Getúlio Vargas, posição que manteve por 48 anos, como dito anteriormente (vide nota 13).

Na formulação de políticas públicas focadas no cientificismo e no racionalismo, o DASP propunha uma mudança nas relações de trabalho, em voga em outros países, onde a ciência administrativa se consolidava em universidades, assim como a administração pública se tornava objeto de estudos em cursos. Assim, procurava adaptar realidades de outros países com a realidade brasileira, que na prática eram incompatíveis e objeto de crítica dentro da administração pública federal. Os funcionários do DASP vislumbravam um serviço público eficiente e ordenado, focado em aspectos burocráticos e na capacitação de servidores como motes para mudanças profundas e com regras de sociabilidade no trabalho, mas que tiveram pouco alcance. Porém, nas décadas de 1930 e 1940, esse Departamento não deixou de ser uma instância importante que pensou o papel da ciência administrativa no serviço público, além de ter produzido uma mentalidade organizacional, aumentado substancialmente o número de concursos públicos no país, ${ }^{42}$ consolidado teorias de

41 RABELO, op. cit., 2013. p. 180-182.

42 A partir dos dados presentes no relatório da Divisão de Seleção de 1943, é possível perceber o progressivo aumento de número de concursos públicos e candidatos. Em 1937, eram 140 candidatos inscritos em três concursos públicos. Em 1938, esse número subiu para 5.784, em 9 seleções. Em 1943, tem-se 40.448 candidatos em 43 concursos públicos e 263 habilitações (para extranumerários). DASP. Relatório da Divisão de Seleção. Relatórios, administração interna. Pastas 34 e 35, 1943. Arquivo Nacional, Rio de Janeiro. 
personnel management no serviço público e de pensar no papel da expertise e do conhecimento na construção de políticas públicas. Produziu, como efeito não antecipado, núcleos de expertise entre trabalhadores no serviço público federal, que se voltavam para a produção de relatórios e análises de infraestruturas e de instituições públicas, especialmente na década de 1950.

Nesse sentido, ao introduzir o discurso da expertise de forma ampla nas políticas de Estado, o DASP promoveu uma nova visão sobre o serviço público, conjugando o conhecimento técnico às ações do Estado, almejando, assim, uma nova visão dos trabalhadores da administração pública brasileira.

Recebido em 31/07/2019

Aprovado em 21/10/2019 